\title{
RANCANG BANGUN SISTEM PENDUKUNG KEPUTUSAN PENENTUAN JUMLAH PRODUKSI MENGGUNAKAN METODE FUZZY TSUKAMOTO
}

\author{
ROHMAT TAUFIQ, ${ }^{1)} \&$ HESTI PUSPITA SARI ${ }^{2)}$ \\ Program Studi Informatika \\ Fakultas Teknik Universitas Muhammadiyah Tangerang \\ Jl. Perintis Kemerdekaan 1/33 Cikokol Kota Tangerang \\ Email: rohmat.taufiq@yahoo.com, ${ }^{1)}$ hestipsf1@gmail.com ${ }^{2)}$
}

\begin{abstract}
ABSTRAK
Industri konveksi baju adalah suatu perusahaan yang menghasilkan pakaian jadi seperti pakaian wanita, pakaian pria, pakaian anak-anak, pakaian olahraga maupun pakaian-pakaian politik. Industri konveksi bisa dibilang perusahaan yang sedang karena tenaga kerjanya masih dibilang sedikit. Ketidak-stabilannya pemesanan yang tinggi pada waktu tertentu dan rendah pada waktu tertentu mengakibatkan sulitnya menentukan jumlah produksi yang tepat. Ketidaktepatan jumlah produksi sangat berpengaruh terhadap tingkat kerugian yang diakibatkan kurangnya pekerja, karena jumlah produksi barang yang terlalu rendah ataupun berlebihan. Masalah ini bisa diselesaikan dengan mengembangkan sebuah aplikasi dalam sistem pendukung keputusan. Adapun teknik yang dapat diterapkan dalam mengembangkan sistem pendukung keputusan ini adalah fuzzy Tsukamoto. Aplikasi ini diterapkan dalam menentukan jumlah produksi, dengan variabel permintaan, pekerja dan produksi. Setiap variabel terdiri dari dua himpunan yang di kombinasikan hingga diperoleh sembilan aturan fuzzy, yang selanjutnya digunakan dalam tahap inferensi. Pada tahap inferensi, dicari nilai keanggotaan anteseden $(\alpha)$ dan nilai perkiraan jumlah produksi (z) dari setiap aturan. Jumlah barang yang akan diproduksi (Z) dicari dengan metode defuzzifikasi rata-rata terpusat. Dalam penelitian ini dibuktikan dengan tabel perbandingan antara perhitungan manual dengan perhitungan sistem, dan didapatkan hasil persentase kebenaran dari sistem ini adalah sebesar $96 \%$.
\end{abstract}

Kata Kunci: Sistem Pendukung Keputusan, Fuzzy Inference System Tsukamoto, Penentuan Jumlah Produksi.

\section{PENDAHULUAN}

Industri konveksi baju adalah suatu perusahaan yang menghasilkan pakaian jadi seperti pakaian wanita, pakaian pria, pakaian anakanak, pakaian olahraga maupun pakaian-pakaian politik. Industri konveksi bisa dibilang perusahaan yang sedang karena tenaga kerjanya masih dibilang sedikit.

Ketidakstabilannya pemesanan yang tinggi pada waktu tertentu dan rendah pada waktu tertentu mengakibatkan sulitnya menentukan jumlah produksi yang tepat. Ketidaktepatan jumlah produksi sangat berpengaruh terhadap tingkat kerugian yang diakibatkan kurangnya persediaan, karena jumlah produksi barang yang terlalu rendah, ataupun berlebihannya persediaan barang karena jumlah produksi yang terlalu tinggi dan juga faktor pekerja pun mempengaruhi proses produksi tersebut.

Penentuan jumlah produksi dalam perusahaan merupakan suatu hal yang harus diperhatikan sebelum memulai sebuah proses produksi. Perlu dipertimbangkan berbagai faktor untuk menentukan jumlah produksi barang, untuk menghindari risiko perusahaan. Untuk menyelesaikan masalah tersebut, pihak perusahaan, dalam hal ini manajer, hendaknya dapat membuat suatu keputusan yang tepat untuk memilih berapa banyak jumlah produk yang diproduksi untuk mengoptimalkan keuntungan suatu perusahaan. Maka, dibutuhkan 
suatu sistem pendukung keputusan untuk membantu para manajer tersebut.

Perangkat lunak dalam sistem pendukung keputusan yang akan dikembangkan menggunakan metode fuzzy Tsukamoto. Perangkat lunak ini akan diterapkan dalam menentukan jumlah produksi. Hasil perhitungan fuzzy Tsukamoto akan didapatkan output yang berupa jumlah barang yang akan di produksi sehingga perusahaan dapat meminimalisir kerugian yang dihadapi.

Adapun tujuan penelitian adalah: 1) Merancang sistem pendukung keputusan penentuan jumlah produksi di CV. Firdilla Zenaf; 2) Membantu pihak CV. Firdilla Zenaf membuat keputusan dengan menggunakan sistem pendukung keputusan yang dapat melakukan perhitungan terhadap jumlah produksi; dan 3). Mengimplemen-tasikan sistem yang sudah dibuat ke CV. Firdilla Zenaf.

\section{TINJAUAN PUSTAKA}

1. Pengertian Sistem

Menurut Gordon (2012:17), sistem bisa berupa abstrak atau fisis. Sistem yang abstrak adalah susunan yang teratur dari gagasangagasan atau konsepsi yang saling bergantung. Sedangkan sistem yang bersifat fisis adalah serangkaian unsur yang bekerja-sama untuk mencapai suatu tujuan.

2. Pengertian Sistem Pendukung Keputusan Menurut Vercellis (2009:36), Sistem Pendukung Keputusan (SPK) merupakan aplikasi interaktif berbasis komputer yang mengkombinasikan data dan model matematis untuk membantu proses pengambilan keputusan dalam menangani suatu masalah.

\section{Fuzzy Inference System Tsukamoto}

Menurut Kusumadewi (2010), pada metode Tsukamoto, setiap konsekuen pada aturan yang berbentuk IF-THEN harus direpresentasikan dengan suatu himpunan fuzzy dengan fungsi keanggotaan yang monoton. Sebagai hasilnya, output hasil inferensi dari tiap-tiap aturan diberikan dengan tegas (crips) berdasarkan $\alpha$-predikat (fire strength). Hasil akhirnya diperoleh dengan menggunakan rata-rata terbobot. Misalkan ada dua variabel input, yaitu x dan y; serta satu variabel output z. Variabel $\mathrm{x}$ terbagi atas dua himpunan yaitu A1 dan A2, sedangkan variabel y terbagi atas himpunan B1 dan B2. Variabel z juga terbagi atas dua himpunan yaitu $\mathrm{C} 1$ dan $\mathrm{C} 2$.

\section{METODELOGI PENELITIAN \\ 1. Jenis Penelitian}

Data-data primer yang akan penyusun kumpulkan adalah data yang berhubungan dengan penentuan produksi barang yaitu berupa data permintaan, data pekerja dan data produksi. Data-data yang dimanfaatkan adalah data yang diambil dari bulan Januari 2017 sampai dengan Desember 2017.

Dalam mengumpulkan data primer, penulis menggunakan beberapa metode yaitu:

1. Metode pengamatan langsung, yaitu dengan cara melakukan pengamatan secara langsung terhadap proses permintaan dan melihat banyaknya pekerja sampai dengan proses produksi barang tersebut sehingga bisa ditentukan berapa banyak produk yang bisa di hasilkan.

2. Metode wawancara, dilakukan dengan cara tanya jawab secara langsung dengan narasumber yang mengetahui proses penentuan jumlah produksi.

\section{Metode Pengolahan Data}

Berdasarkan data penjualan setiap bulannya, data yang diambil adalah data variabel permintaan, data variabel pekerja dan data variabel produksi dari bulan Januari 2017 dan Desember 2017.

\begin{tabular}{|c|l|c|c|c|}
\hline No. & Bulan (Tahun) & Permintaan & Pekerja & Produksi \\
\hline 1 & Januari 2017 & 5700 & 8 & 5500 \\
\hline 2 & Februari 2017 & 6000 & 9 & 6000 \\
\hline 3 & Maret 2017 & 7000 & 11 & 8500 \\
\hline 4 & April 2017 & 7000 & 10 & 8000 \\
\hline 5 & Mei 2017 & 6500 & 10 & 8000 \\
\hline 6 & Juni 2017 & 8000 & 10 & 8000 \\
\hline 7 & Juli 2017 & 8000 & 12 & 8000 \\
\hline 8 & Agustus 2017 & 8200 & 9 & 8500 \\
\hline 9 & September 2017 & 8900 & 14 & 10000 \\
\hline 10 & Oktober 2017 & 9150 & 11 & 11000 \\
\hline 11 & Nopember 2017 & 9300 & 12 & 10000 \\
\hline 12 & Desember 2017 & 9700 & 15 & 11500 \\
\hline
\end{tabular}

Tabel Himpunan Fuzzy

\begin{tabular}{|c|c|c|c|c|}
\hline Fungsi & Variabel & Himpunan Fuzzy & $\begin{array}{c}\text { Semesta } \\
\text { Pembicara }\end{array}$ & Domain \\
\hline \multirow{6}{*}{ Input } & \multirow{3}{*}{ PMT } & Turun & \multirow{3}{*}{$3000-8250$} & $3000-5500$ \\
\hline & & Biasa & & $4250-6750$ \\
\hline & & Naik & & $5500-8250$ \\
\hline & \multirow{3}{*}{ PKJ } & Sedikit & \multirow{3}{*}{$7-15$} & $7-11$ \\
\hline & & Sedang & & $9-13$ \\
\hline & & Banyak & & $11-15$ \\
\hline \multirow{2}{*}{ Output } & \multirow{2}{*}{ PRD } & Berkurang & \multirow{2}{*}{$5500-11500$} & $5500-11500$ \\
\hline & & Bertambah & & $5500-11500$ \\
\hline
\end{tabular}

\section{Perancangan Inference Fuzzy}

a) Variabel Permintaan

Pada variabel permintaan didefinisikan tiga himpunan fuzzy, yaitu: TURUN, BIASA, NAIK. Untuk mempresentasikan variabel 
permintaan digunakan bentuk kurva bahu kiri untuk himpunan fuzzy TURUN, bentuk kurva segitiga untuk himpunan BIASA, dan bentuk bahu kanan untuk himpunan fuzzy NAIK.

$$
\begin{aligned}
& \mu \text { Turun }(a)= \begin{cases}1 & ; \mathrm{a} \leq 3000 \\
\frac{5500-\mathrm{a}}{2500} & ; 3000 \leq \mathrm{a} \leq 5500 \\
0 & ; \mathrm{a} \geq 5500\end{cases} \\
& \mu \text { Biasa }(a)= \begin{cases}\frac{\mathrm{a}-4250}{2500} & ; 4250 \leq \mathrm{a} \leq 5500 \\
\frac{6750-\mathrm{a}}{2500} & ; 5500 \leq \mathrm{a} \leq 6750\end{cases} \\
& \mu \text { Naik (a) }= \begin{cases}0 & ; \mathrm{a} \leq 5500 \\
\frac{\mathrm{a}-5500}{2750} & ; 5500 \leq \mathrm{a} \leq 8250 \\
1 & ; \mathrm{a} \geq 8250\end{cases}
\end{aligned}
$$

Jika permintaan 8000 , maka:

$$
\begin{aligned}
& \mu \operatorname{Turun}(8000)=0 \\
& \mu \text { Biasa (8000) }=0 \\
& \mu \text { Naik (8000) }=0,909091
\end{aligned}
$$

b) Variabel Pekerja

Pada variabel pekerja didefinisikan tiga himpunan fuzzy, yaitu SEDIKIT, SEDANG, dan BANYAK. Untuk merepresentasikan variabel pekerja digunakan bentuk kurva bahu kiri untuk himpunan fuzzy SEDIKIT, bentuk kurva segitiga untuk himpunan fuzzy SEDANG, dan bentuk kurva bahu kanan untuk himpunan fuzzy BANYAK.

$\mu$ Sedikit $(b)= \begin{cases}1 & ; b \leq 7 \\ \frac{11-b}{4} & ; 7 \leq b \leq 11 \\ 0 & ; b \geq 11\end{cases}$

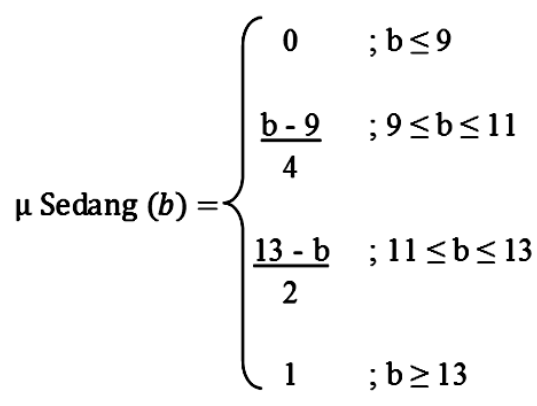

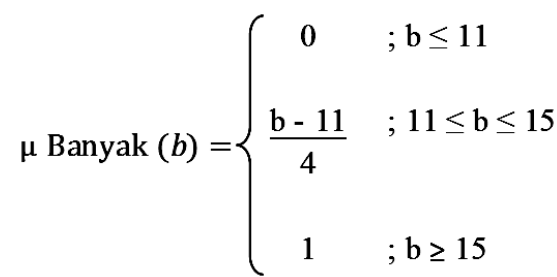

Jika Pekerja 10, maka: $\mu$ Sedikit $(10)=0,25$

$\mu$ Sedang $(10)=0,5$

$\mu$ Banyak (10) $=0$

c) Variabel Produksi

Pada variabel produksi didefinisikan dua himpunan fuzzy, yaitu BERKURANG dan BERTAMBAH. Untuk merepresentasikan variabel produksi digunakan bentuk kurva bahu kiri untuk himpunan fuzzy BERKURANG, dan bentuk kurva bahu kanan untuk himpunan fuzzy BERTAMBAH.

$\mu \operatorname{Bertambah}(c)= \begin{cases}0 & ; \mathrm{c} \leq 5500 \\ \frac{\mathrm{c}-5500}{6000} & ; 5500 \leq \mathrm{c} \leq 11500 \\ 1 & ; \mathrm{c} \geq 11500\end{cases}$

\section{Aplikasi Fungsi Implikasi}

Aturan yang digunakan adalah aturan MIN pada fungsi implikasinya:

[R1] Jika Permintaan TURUN dan Pekerja SEDIKIT maka Produksi BERKURANG

$\alpha$ - predikat $_{1}=\mu$ PmtTURUN $\cap \mu$ PkjSEDIKIT $=$ $\min (0 ; 0,25)=0$

$\mathrm{C} 1=11500$

[R2] Jika Permintaan TURUN dan Pekerja SEDANG maka Produksi BERKURANG 
$\alpha-$ predikat $2=\mu$ PmtTURUN $\cap \mu$ PkjSEDANG

$=\min (0 ; 0,25)=0$

$\mathrm{C} 2=11500$

[R3] Jika Permintaan TURUN dan Pekerja BANYAK maka Produksi BERKURANG

$\alpha-$ predikat $3=\mu$ PmtTURUN $\cap \mu P k j B A N Y A K$

$=\min (0 ; 0)=0$

$\mathrm{C} 3=11500$

[R4] Jika Permintaan BIASA dan Pekerja SEDIKIT maka Produksi BERKURANG

$\alpha-$ predikat $4=\mu$ PmtBIASA $\cap \mu$ PkjSEDIKIT $=\min (0 ; 0,25)=0$

$\mathrm{C} 4=11500$

[R5] Jika Permintaan BIASA dan Pekerja BIASA maka Produksi BERTAMBAH

$\alpha-$ predikat $5=\mu$ PmtBIASA $\cap \mu$ PkjBIASA $=$ $\min (0 ; 0,25)=0$

$\mathrm{C} 5=5500$

[R6] Jika Permintaan BIASA dan Pekerja BANYAK maka Produksi BERTAMBAH

$\alpha$-predikat $6=\mu$ PmtBIASA $\cap \mu$ PkjBANYAK $=\min (0 ; 0)=0$

C6 $=5500$

[R7] Jika Permintaan NAIK dan Pekerja SEDIKIT maka Produksi BERKURANG

$\alpha-$ predikat7 $=\mu$ PmtNAIK $\cap \mu$ PkjSEDIKIT

$=\min (0,909091 ; 0,25)=0.25$

$\mathrm{C} 7=10000$

[R8] Jika Permintaan NAIK dan Pekerja SEDANG maka Produksi BERTAMBAH

$\alpha-$ predikat $8=\mu$ PmtNAIK $\cap \mu$ PkjSEDANG $=\min (0,909091 ; 0,50)=0.50$

$\mathrm{C} 8=8500$

[R9] Jika Permintaan NAIK dan Pekerja BANYAK maka Produksi BERTAMBAH

$\alpha-$ predikat $9=\mu$ PmtNAIK $\cap \mu$ PkjBANYAK $=\min (0,909091 ; 0)=0$

C9 $=5500$

\section{Defuzzifikasi}

$$
\begin{aligned}
Z_{0} & =\frac{\boldsymbol{\propto}_{1} Z_{1}+\boldsymbol{\aleph}_{2} Z_{2}}{\boldsymbol{\alpha}_{1}+\boldsymbol{\alpha}_{2}} \\
& =\frac{0.25 * 10000+0.50 * 8500}{\mid 0.25+0.50} \\
& =\frac{6750}{0.75} \\
& =9000
\end{aligned}
$$

\section{HASIL PENELITIAN}

\section{Prosedur Sistem Berjalan}

Analisa prosedur sistem yang berjalan akan menjelaskan tentang proses bisnis prosedur dan kegiatan pada sistem yang sedang berjlan di CV. Firdilla Zenaf. Prosedur yang dilakukan diantaranya:

1. Prosedur Pengelolahan Produksi.

2. Prosedur Pengelolahan Pekerja.

3. Prosedur Perencanaan Produksi Barang.

\section{Perancangan Sistem Usulan}

Berdasarkan pembahasan pada bab sebelumnya, maka diusulkan suatu perancangan sistem yang baru bertujuan untuk memberikan solusi yang lebih baik dari sistem yang sebelumnya. Berikut penggambaran sistem dengan use case diagram:

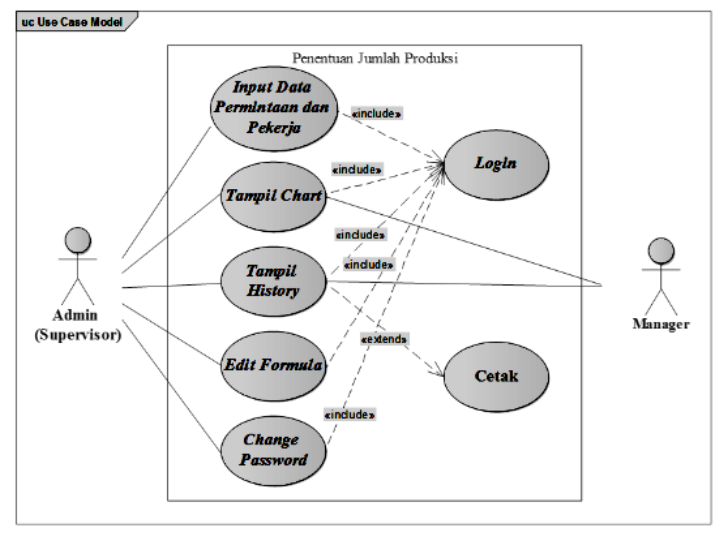

\section{Implementasi Sistem}

a) Tampilan Form Login

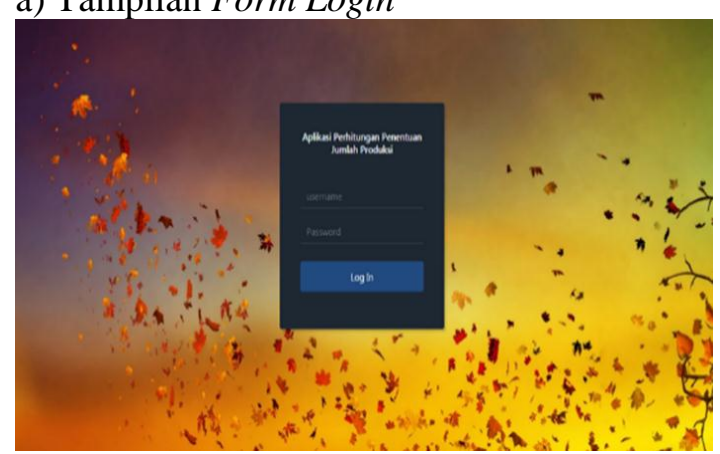


b) Tampilan Menu Input

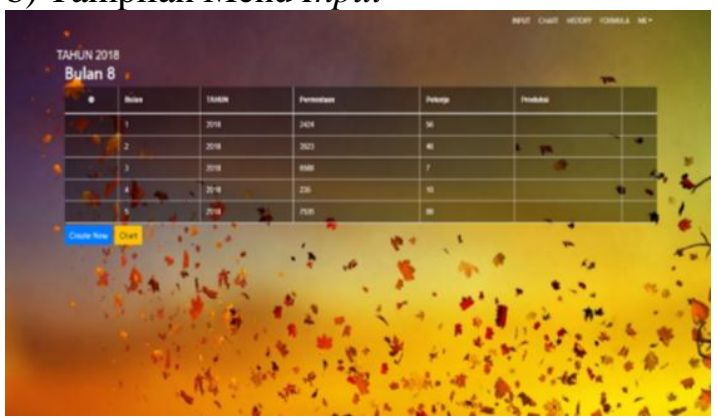

c) Tampilan Menu Chart

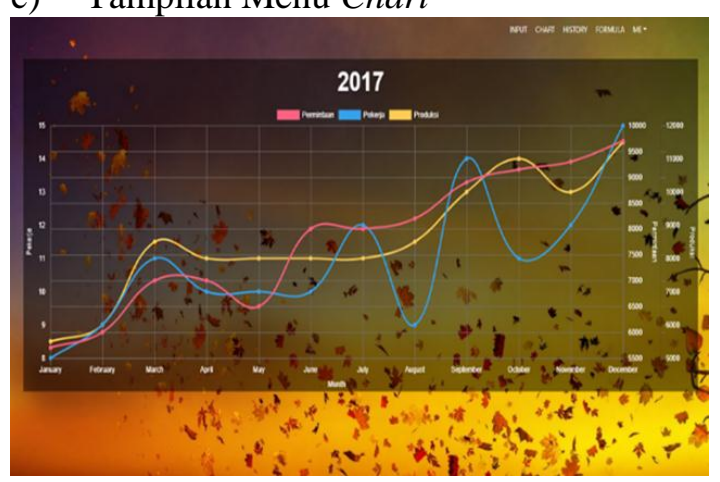

d) Tampilan Menu History

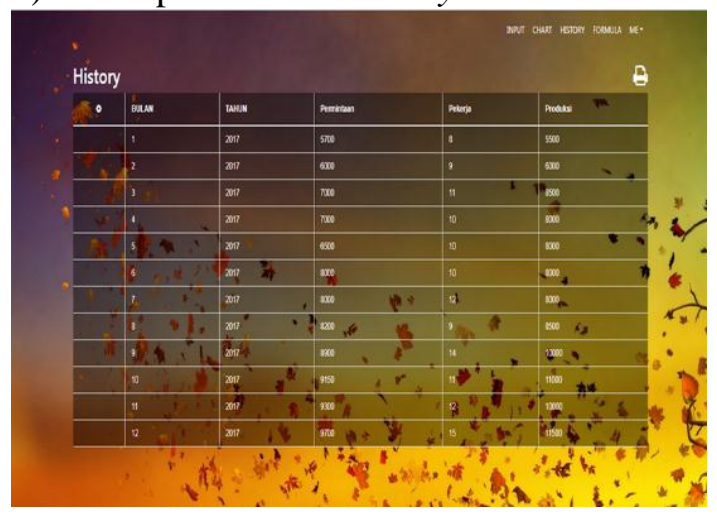

e) Tampilan Menu Formula

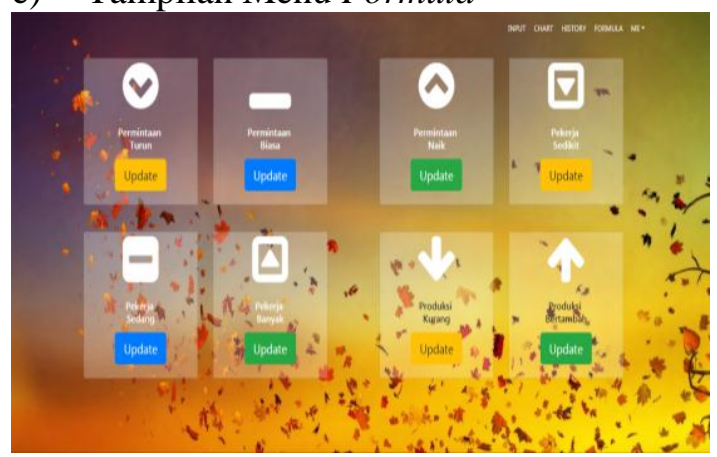

f) Tampilan Form Change Password

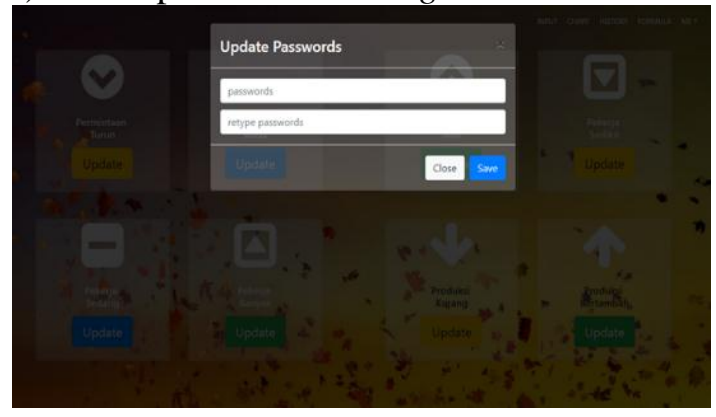

\section{KESIMPULAN}

Dari pembahasan yang sudah diuraikan maka penulis mencoba membuat kesimpulan seperti berikut ini:

1. Penggunaan logika fuzzy pada sistem yang nilai input-nya tidak pasti mampu menghasilkan output crisp, karena logika fuzzy memiliki toleransi terhadap datadata yang tidak tepat.

2. Dalam penelitian ini dibuktikan dengan tabel perbandingan antara perhitungan manual dengan perhitungan sistem, dan didapatkan hasil persentase kebenaran dari sistem ini adalah sebesar $96 \%$.

3. Sistem ini hanya sebatas alat bantu dalam penentuan jumlah produksi, tetapi keputusan penentuan jumlah produksi tetap berada di pihak perusahaan.

\section{DAFTAR PUSTAKA}

Kusumadewi, Sri dan Purnomo Hari. 2010, “Aplikasi Logika Fuzzy", Cetakan Pertama, Graham Ilmu, Yogyakarta.

Sutabri, Tata. 2012. "Konsep Dasar Informasi". Yogyakarta: Andi

Vercellis, Carlo. (2009). Business Intelligence: Data mining and optimization for decision making. Chichester: John Wiley \& Sons. 